\title{
APLICACÃO DE INTERFACES INTELIGENTES PARA FLEXIBILIZACÃO E OTIMIZAÇÃO NA LINHA DE MONTAGEM DE AUTOMÓVEIS: UM ESTUDO NA PLANTA ANCHIETA DA VOLKSWAGEN DO BRASIL
}

\section{APPLICATION OF INTELLIGENT INTERFACES FOR FLEXIBILITY AND OPTIMIZATION IN CAR ASSEMBLY LINE: A STUDY AT THE ANCHIETA'S PLANT OF VOLKSWAGEN OF BRAZIL}

\author{
Ricardo Kenji Oi* E-mail: ricardo.oi@unisantos.br \\ Débora Agráz Cutino Nogueira*E-mail: debora.agraz@unisantos.br \\ José Fontebasso Neto* E-mail: jfneto@unisantos.br \\ Cláudio Rodrigo Torres** E-mail: c.r.t@uol.com.br \\ João Inácio da Silva Filho*** E-mail: inacio@unisanta.br \\ *Universidade Católica de Santos - Grupo de Pesquisa GPOLog, Santos/SP \\ ${ }^{* *}$ Universidade Metodista, São Paulo/SP \\ ***Universidade Santa Cecília - Programa de Pós-graduação em Engenharia Mecânica, Santos/SP
}

Resumo: O presente trabalho traz um estudo para a obtenção da flexibilização das linhas de montagem na planta Anchieta da Volkswagen do Brasil. Para a implantação da flexibilização foram utilizadas quatro interfaces inteligentes para controlar restrições e distribuições do mesmo modelo de automóvel produzido em duas linhas produtivas, obedecendo as restrições técnicas para alguns acabamentos específicos e visando atingir a meta de produção nessas duas linhas. Estas interfaces eram responsáveis pela identificação do produto, analisar as restrições técnicas, assegurar que não exista ordem de produção duplicada e calcular a quantidade no circulante pelo volume entre o ponto de início de montagem até o ponto de escolha de linha. Essa implementação foi fundamental para que a empresa conseguisse utilizar as duas linhas de montagem para produzir o modelo Gol básico, atendendo assim a sua meta de produção diária e otimizando o processo produtivo.

Palavras-chave: Identificação. Restrições. Interface inteligente. Decisão. Flexibilidade.

Abstract: This article presents a study to obtain the flexibility of the assembly lines in the Anchieta's plant of Volkswagen of Brazil. Four Intelligent interfaces were used to implement the flexibility to control constraints and distributions of the same car model produced in two assembly lines, obeying the technical restrictions for some specific finishes and pursuit of the goal of production in these two lines. These interfaces are responsible for making the identification of the product, analyze technical constraints, ensure that there is no production order duplicate and calculate the amount circulating in the volume between the start point mounting to the point of choosing line. This implementation was key to the company could use two assembly lines to produce the basic Gol model, thus reaching its daily production target and optimizing its production process.

Keywords: Identification. Constraints. Intelligent interfaces. Decision. Flexibility.

\section{INTRODUÇÃO}


A elevada competição pelos mercados, assim como a necessidade de agregação de valor têm impulsionado as indústrias dos mais diversos setores a implantar processos cada vez mais otimizados, com taxas mínimas de perdas e máximas em qualidade e produtividade.

O planejamento industrial possui um papel muito importante neste cenário, sempre se atentando a disposição física das máquinas, áreas e circulação, equipamentos, áreas de estoque e pessoas, fatores os quais, influenciam diretamente na eficiência de uma operação. Nesse contexto, o alcance da excelência operacional torna-se o grande desafio para as organizações.

Dentre as ferramentas disponíveis para os gestores enfrentarem esse desafio encontra-se a teoria das restrições ou Theory of Constraints (TOC), termo em inglês, que foi amplamente difundido no meio organizacional em 1984, através do livro The Goal (A Meta) de Eliyahu Goldratt e Jeff Cox (SPENCER e COX, 1995).

Goldratt e Cox (2002) definem a Teoria das Restrições como uma filosofia global de gerenciamento empresarial com o propósito de promover a contínua otimização do desempenho esperado de qualquer entidade que tenha uma meta bem definida, através do enfoque das ações gerenciais nos elementos que a restringem.

A teoria das restrições é um processo de pensamento que pode ser aplicado para ajudar as organizações a identificar os problemas, encontrar as estratégias para resolvê-los e, eventualmente, implementar essas estratégias com sucesso (MABIN e BALDERSTONE, 2003).

A característica mais importante da TOC é assumir que em qualquer sistema existe pelo menos uma restrição, algo que limita um desempenho melhor ou o impede de atingir um elevado padrão. Caso não houvesse restrição o desempenho dos sistemas seriam ilimitados (CORBETT, 2005).

Conceitos como MRP, SCM, JIT e ERP são ferramentas bem difundidas e consagradas na área de gestão de operações em todo mundo. A TOC é um conceito mais recente, que tem evoluído desde a sua difusão iniciada na década de 80 (CHOU et al. 2012).

Gupta e Snyder (2009) compararam a TOC com os conceitos de JIT e MRP através de estudo bibliográfico. A TOC evoluiu de programação software da década de 1980 em uma filosofia de gestão global para estabelecer filosofias de manufaturas 
estabelecidas como MRP e JIT. Quando a TOC é comparada com o MRP, reconhece a sua contribuição, mas poderia ser integrado com um sistema MRP já existente. Por sua vez, na comparação da teoria da restrição com o JIT, o princípio japonês é mais adequado para ambientes caracterizados pela produção repetitiva.

A TOC é semelhante ao JIT funcionando sob a técnica de produção puxada chamada de drum-buffer-rope (DBR) ou tambor-pulmão-corda para coordenar e movimentar o controle de inventário da fábrica (LAMBRECHT e SEGAERT, 1990).

O tambor é a restrição cujo conjunto de programação define o ritmo de produção para o sistema. A corda liga o recurso de restrição com a operação, controlando assim a liberação de materiais a um ritmo ditado pelo consumo de materiais na restrição. Em conjunto com a corda, o tambor é capaz de limitar o inventário do sistema. Já a finalidade do pulmão é fornecer proteção para a saída da restrição, atuando como um amortecedor contra flutuações estatísticas. Em vez de limitar o movimento de materiais entre máquinas como o kanban, o DBR opera sob um sistema quando o trabalho está disponível (WATSON e PATTI, 2008).

Spector (2011) desenvolveu um estudo combinando a teoria das restrições e o Business Model (BM); quando aplicadas em conjunto, esses conceitos permitem analisar e controlar as restrições de forma a proporcionar ganhos de eficiência operacional para a organização.

Coman e Ronen (2007) estenderam a TOC para lidar com restrições estratégicas através de cinco passos para alinhar as competências essenciais da organização com os principais fatores de sucesso da área de negócios: (1) identificar as restrições da organização; (2) identificar as restrições estratégicas da área de negócios; (3) analisar a diferença entre a organização e as restrições; (4) esboçar um plano de ação alinhando a organização em sua área de negócios; (5) executar o plano de ação e acompanhar a sua eficácia.

Souza (2005) esclarece alguns aspectos bastante particulares da TOC, especificamente relacionados com a sua proposta de programação da produção baseada na capacidade finita dos recursos fabris, através do Tambor-Pulmão-Corda. O autor também apresenta que a lógica inerente ao DBR não necessariamente é a mesma do software OPT (Optimum Production Technology). 
Ainda existe uma confusão entre o software de programação da produção denominado OPT e a TOC. Spencer e Cox (1995) apresentaram as dúvidas entre os dois conceitos em três áreas: a primeira é que o TOC está substituindo o OPT; a segunda diz respeito área que compõem os dois métodos, em que até o momento não houve nenhuma categorização clara dos elementos que estão na TOC que a torna diferente do OPT; a terceira é a confusão de alguns dos conceitos práticos apresentados no livro The Goal, especialmente nos métodos de programação.

$\mathrm{O}$ conceito de OPT foi originalmente apresentado como software em um conjunto de regras de programação e acabou tornando-se questionamento das bases do planejamento e controle da produção, pois desafiava os indicadores de desempenho tradicionais da contabilidade de custos, gerencial e de negócios ( $\mathrm{COX}$ e SPENCER, 2002).

A TOC pode ser aplicada em diversas situações para o gerenciamento eficiente dos recursos. Sobreiro e Nagano (2012) abordaram o problema da otimização de mix de produtos sob a teoria das restrições, por meio de heurísticas construtivas; os resultados computacionais indicaram que a heurística proposta pelo modelo produz melhores resultados que a heurística existente.

Chou et al. (2012) analisaram a TOC em uma indústria aeroespacial para diagnosticar os efeitos indesejáveis de sistemas de gestão de materiais e identificar problemas de raiz ou ações de manejo de material conflitantes. Ao eliminar o inventário conflitantes de atividades de diferentes departamentos de gestão, o desempenho do gerenciamento de inventário de todo o sistema foi melhorado. Para os referidos autores, a empresa pode usar a teoria da restrição regularmente para ver o defeito ou falha antes de prosseguir com alto custo de gerenciamento de inventário.

Babu et al. (2007) aplicaram a teoria das restrições para identificar a criticidade de máquinas CNCs em uma indústria de autopeças, utilizando a programação inteira. No estudo foi possível que a fábrica cumprisse a demanda sem a necessidade de investimentos em novas máquinas.

Votto e Fernandes (2014) fizeram a implantação conjunta dos princípios da produção enxuta e da teoria das restrições, com a utilização dos sistemas de coordenação de ordens adequados, com a finalidade de redução do lead time de produção e melhorar a pontualidade de entrega. 
Torres e Costa (2013) aplicaram a TOC para o planejamento do sistema de produção em uma empresa de confecção; no estudo foi possível identificar e reduzir os gargalos de produção, além de possibilitar a escolha da opção mais adequada para a configuração do sistema de produção.

Triana e Rolón (2014) utilizaram a teoria das restrições em uma indústria de calçados; as restrições do sistema produtivo foram identificadas e foi desenvolvido um modelo matemático através da programação linear. Como resultado da pesquisa, o modelo desenvolvido conseguiu determinar a quantidade ótima de produção e a maximização dos lucros.

Scholz et al. (2012) aplicaram a TOC em uma indústria de blindagem de veículos, em que foram identificadas as restrições e, com base nessas informações, tomaram-se as decisões visando utilização da capacidade instalada, com a manutenção das despesas operacionais ou da redução da grande diversidade de veículos a serem blindados.

Pergher et al. (2011) apresentaram uma reflexão teórica a respeito dos possíveis impactos nos indicadores TOC provocados pelas sete perdas abordadas no Sistema Toyota de Produção (STP) e pela perda por má definição do mix de produtos influenciada pelo uso de métodos inadequados para formular essa variedade de itens. O trabalhou fundamentou as relações impactantes e possibilitou a proposição de ações de melhoria tendo por objetivo minimizar os impactos apresentados. Este tema é encorajado pela atual dinâmica dos mercados, nos quais a importância do desenvolvimento do mix ótimo de produtos, que possibilita o lucro máximo e provoca influência nos pilares da sustentabilidade da organização.

Pacheco et al. (2012) apresentaram um modelo de gerenciamento da capacidade produtiva em sistemas produtivos integrando os conceitos da TOC e da Total Productive Maintenance (TPM), em que foi possível determinar a capacidade do sistema produtivo e o impacto sobre a capacidade produtiva de todo o sistema, ao se considerar as não conformidades de qualidade que ocorrem após o recurso gargalo do fluxo produtivo.

Silva et al. (2017) aplicaram a Teoria das Restrições utilizando seus cinco passos em uma indústria de colchões situada no Rio Grande do Sul. Os resultados encontrados relacionaram-se com a identificação dos gargalos, noção do processo 
gargalo e sua eliminação, de modo a obter ganhos significativos em produtividade, melhorando-se assim a performance da unidade fabril.

Neves et al. (2020) analisaram a implementação da TOC para um gargalo não físico de uma indústria de laticínio de Minas Gerais, por meio de um estudo de caso. O trabalho permitiu aumentar a lucratividade da organização através do combate à restrição limitadora do sistema, que, no caso, foi identificado como o modelo de previsão de demanda da linha refrigerada.

A teoria das restrições também é aplicada com sucesso no setor de serviços. Araújo (2013) identificou a melhoria sistêmica de toda a cadeia produtiva, maximizando os recursos geradores de riquezas através da identificação e do gerenciamento do gargalo no sistema por meio da aplicação da TOC em um hospital. Dalci e Kosan (2012) desenvolveram um estudo que aplicou a teoria das restrições com o objetivo de analisar e melhorar as operações de um hotel, tendo em vista adaptar as estratégias apropriadas para a melhoria do desempenho. Sabbadini et al. (2006) elaboraram uma proposta de melhoria para a redução do tempo entre o registro do paciente de urgência e o início do seu efetivo tratamento, em um hospital de emergência aplicando a TOC na identificação de gargalos e desenvolvido um modelo de simulação a eventos discretos.

A otimização linhas de processo é uma prática eficiente e necessária nas indústrias, principalmente naquelas que têm um mesmo produto fabricado em linhas de montagem distintas, em que uma delas possui restrições e ambas precisam atender a meta do volume de produção planejado.

Utilizando a tecnologia de produção otimizada e a teoria das restrições, a interface inteligente é a responsável por identificar o produto, analisar as restrições técnicas, assegurar que não existe ordem de produção duplicada e calcular a quantidade no circulante pelo volume entre o ponto de início de montagem até o ponto de escolha de linha.

O presente trabalho teve como objetivo apresentar a aplicação do Data Capture Point (DCP) ou pontos de captura de dados instalados em duas linhas de montagem distintas de modelos de automóveis, em que um dos produtos com várias características de acabamento precisa ser processado nessas duas linhas. Uma das 
linhas possui restrições de operação e ambas precisam atingir a meta de produção sem comprometer o volume de fabricação dos demais modelos.

\section{APLICAÇÃO DA TOC E OPT NA LINHA DE MONTAGEM DE AUTOMÓVEIS}

A indústria automobilística tem como característica renovar e/ou lançar novos modelos de automóveis constantemente. Atualmente, essa renovação tem sido mais frequente dada a forte concorrência de novos lançamentos das montadoras. Em muitos casos as linhas de fabricação são mantidas para a produção do novo modelo, em outros é necessário a concepção de uma nova linha.

Uma situação atípica é a fabricação de um determinado modelo em duas linhas distintas dentro de uma mesma planta industrial. A identificação da linha que será montado um modelo necessita ser realizada de forma automática, assim como o controle em tempo real do processo a fim de se atingir o volume de produção planejado.

Esta pesquisa teve como objeto de estudo a planta Anchieta da Volkswagen do Brasil, localizada na cidade de São Bernardo do Campo. O foco do trabalho foi em duas linhas de montagem final. Essa etapa do processo é aquela que há a maior agregação de valor, no qual um automóvel pode receber até quatro mil itens.

A linha A é a responsável pela fabricação das carrocerias dos modelos Polo, Saveiro e Gol G6, enquanto a linha B produz somente o modelo Gol G4 nas versões duas e quatro portas; essa linha é mais antiga, com alguns processos ainda manuais, e por isso os demais modelos não podem utilizá-la, devido às restrições técnicas.

No processo de montagem as carrocerias provêm de uma única linha de pintura, sendo posteriormente destinada para a linha correta de montagem ( $A$ ou $B$ ), através da identificação da carroceria. A Figura 1 ilustra a leitura através das interfaces inteligentes para a destinação correta dos modelos.

Figura 1 - Leitura através das interfaces inteligentes

Revista Produção Online. Florianópolis, SC, v. 20, n. 3, p. 749-771, 2020. 


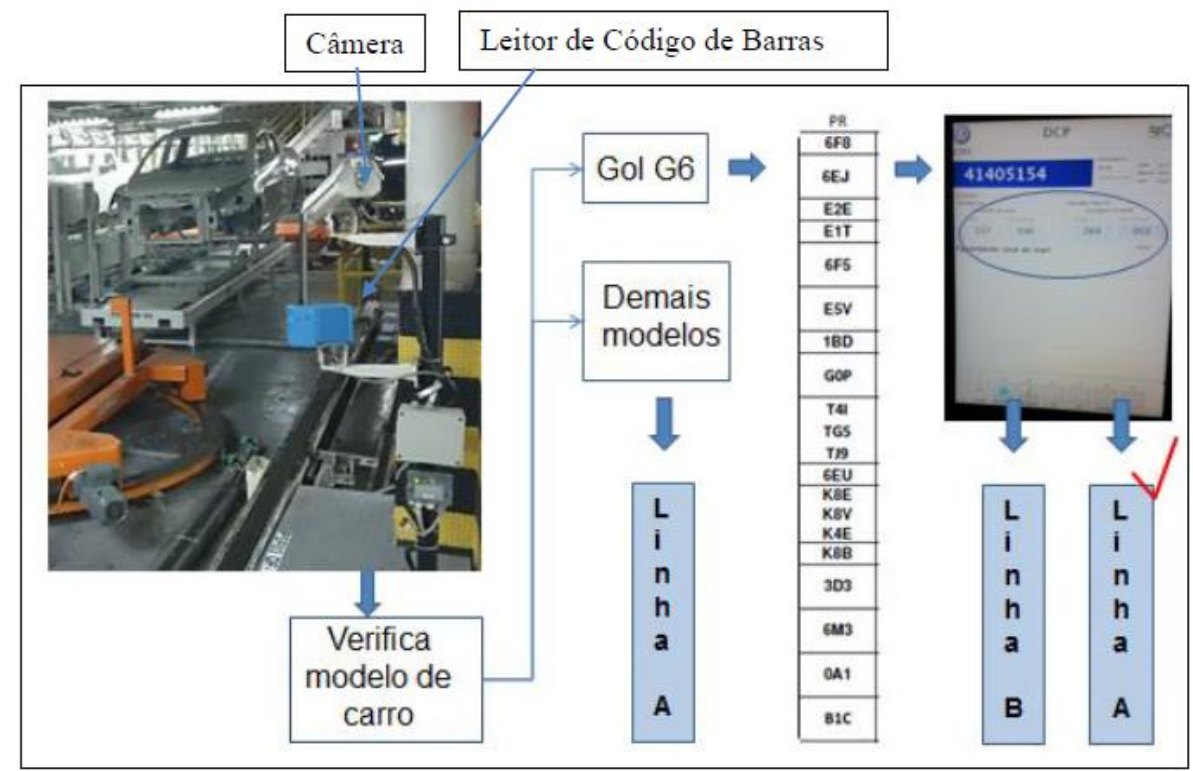

Fonte: Autores

Para um bom aproveitamento das linhas é necessário um controle automático e uma distribuição inteligente de volume conforme a necessidade da empresa. Este volume é controlado pelo PCP que pode ser mudado durante os turnos de processo, conforme a demanda ou estratégia de emergência devido a falhas de fornecedores, como a falta de peças. Nesse caso é necessário que se tenha um processo eficiente que possa ser alterado a qualquer momento, de maneira inteligente, utilizando todos os recursos da linha para atender o volume de produção diário.

A montadora estava descontinuando a fabricação do modelo Gol G4 e elevando o volume de produção do modelo G6, sem alterar o volume de produção dos outros produtos. Para cumprir esse objetivo foi necessário desenvolver uma solução que:

a) Permitisse que um mesmo modelo de carro pudesse ser fabricado em duas linhas de montagem, obedecendo as restrições do processo;

b) Garantisse que ambas as linhas pudessem atingir a meta de produção, sem comprometer o volume dos demais modelos, que também estivessem circulando nessas linhas;

c) Controlasse remotamente 0 volume de produção e obtivesse um acompanhamento online dos dados e resultados pela área responsável;

d) Garantisse confiabilidade do sistema, desenvolvendo o plano de contingência para atuar de maneira automática em caso de falhas; Revista Produção Online. Florianópolis, SC, v. 20, n. 3, p. 749-771, 2020. 
e) Otimizasse o processo atual, transformando-o de manual para $100 \%$ automatizado.

Com as restrições técnicas da linha $B$ foi necessário realizar um levantamento criterioso de quais acabamentos não poderiam ser feitos nessa linha.

\section{MATERIAIS E MÉTODOS}

As interfaces inteligentes são utilizadas para apontamento e controle de produção e identificação dos produtos, fazendo interface com as redes industriais e comunicação com outras DCPs. Essas interfaces inteligentes atuam juntamente com o sistema MES (Manufacturing Execution System ou sistema de execução de manufatura) para identificar as restrições e balancear as linhas, com base no volume do circulante do processo, para tomada de decisão automática e assertiva de qual linha deve seguir para obter o melhor resultado.

Os sistemas MES são sistemas de informação que coletam dados do chão de fábrica como tempos de setup e operação, quantidades de produtos produzidos ou estágios das operações em tempo real, que são utilizados para atualizar o PCP das fábricas. O MES pode ser acoplado ao ERP, que não tem a capacidade de enfrentar aspectos como andamento de uma ordem de produção enquanto ela está em processamento e sujeita às incertezas da produção (GIACON e MESQUISTA, 2011).

O ganho da utilização de um sistema MES está na habilidade de capturar dados do chão de fábrica e reagir, através de uma decisão rápida com o objetivo de minimizar perdas. O maior desafio, porém, é estudar os dados e constatar se algum recurso produtivo está provendo dados coerentes.

É usual acontecer relatos de falhas de treinamento, ou até pouco comprometimento, e os dados capturados demonstrarem algum tipo de anomalia que pode provocar uma decisão errada. Esses erros costumam acontecer quando a captura dos dados não é automatizada.

No presente trabalho as interfaces inteligentes foram compostas pelo equipamento Ícaro fabricado pela empresa CSI, que está ilustrado na Figura 2. Tratase de um dispositivo portátil de uso industrial, assemelhando-se a um tablet, que pode ser utilizado para apontamento de dados que tem conexão com sistemas MES e 
comunicação com dispositivos de captura de dados - coletor de código de barras e câmera.

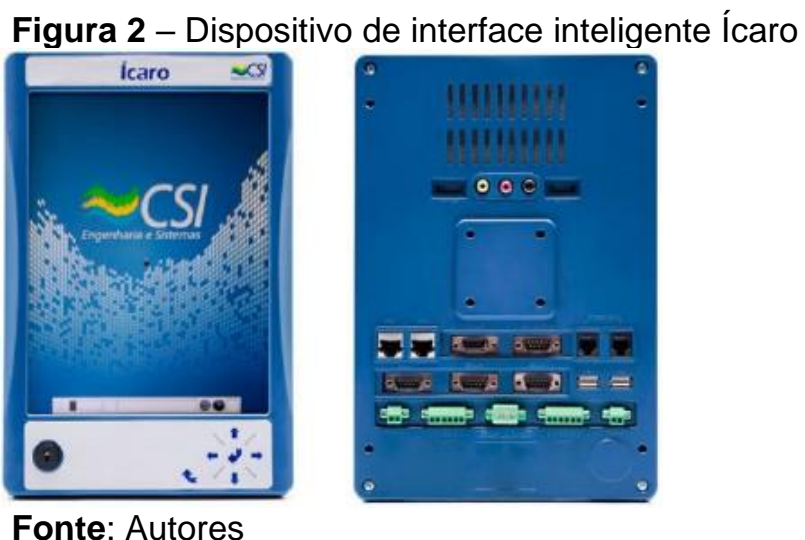

A utilização deste equipamento permite uma boa integração entre sistemas de gestão e o chão de fábrica. Com este propósito, ele conta com visor sensível ao toque para interface com operador e gabinete compacto permitindo simples instalação.

A linha de produção apresentada neste trabalho possui sensores ligados aos controladores lógicos programáveis (CLP) SLC 500 Allen Bradley e S7 400 Siemens responsáveis por informar presença do produto.

Uma vez identificado este produto, a interface inteligente verifica no sistema de execução de manufatura quais são as características de acabamento e se o produto possui ordem de produção duplicada, através de troca de mensagens em protocolo PMON. A solução para otimização de processo foi baseada nas premissas da OPT e da TOC. A Figura 3 ilustra a aplicação desta interface na linha produtiva.

A TOC pôde ser aplicada, pois bastava identificar apenas uma restrição para colocar essa teoria em prática. Para isso, identificaram-se todas as restrições e, posteriormente, gerenciou-se o processo a partir dessas restrições para viabilizar o objetivo da empresa.

Figura 3 - Aplicação da interface inteligente na linha de montagem 


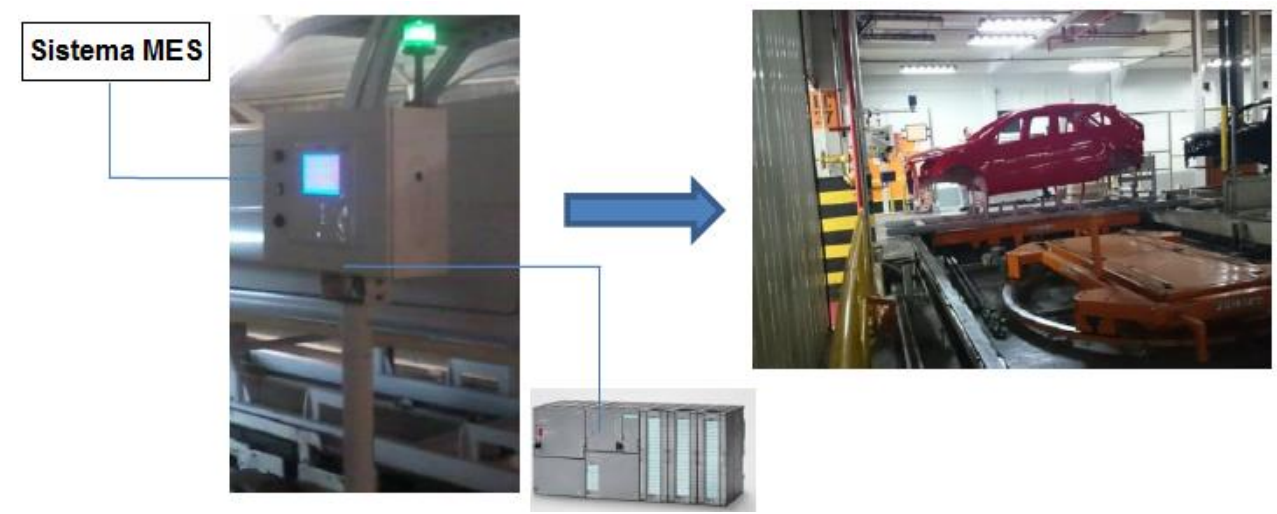

Fonte: Autores

O estudo atuou sobre as duas linhas de montagem para o mesmo produto, sendo uma delas com restrições de acabamentos, fossem balanceadas através das interfaces inteligentes, tendo em vista atingir o volume de produção planejado.

Dessa forma foram instaladas duas interfaces inteligentes chamadas de L760 e L765 compostas do dispositivo Ícaro, que tem conexão com sistemas MES e comunicação com dispositivos de captura de dados (coletor de código de barras e câmera). A Figura 4 apresenta a arquitetura da instalação descrita, em que é possível verificar os coletores de entrada, a interface inteligente e as opções de saída.

As restrições técnicas avaliam as características de acabamento relacionadas ao produto no ponto de decisão. A linha A está preparada para receber somente modelos básicos, enquanto a linha $B$ pode receber modelos básicos e complexos, quanto ao acabamento.

Quando as DCPs identificam produtos de acabamentos básicos, que podem ser montados em ambas as linhas, elas aplicam uma regra de verificação do circulante de cada linha. Se for um modelo com acabamento complexo esse será direcionado automaticamente para a linha "B".

Uma DCP compara os dois valores do circulante, decidindo pelo de menor valor, o que permite que o produto continue, ou não, na própria linha do processo. Para cada linha tem-se uma margem que é aplicada ao cálculo que define a preferência pela linha atual.

Figura 4 - Arquitetura da instalação das interfaces inteligentes 


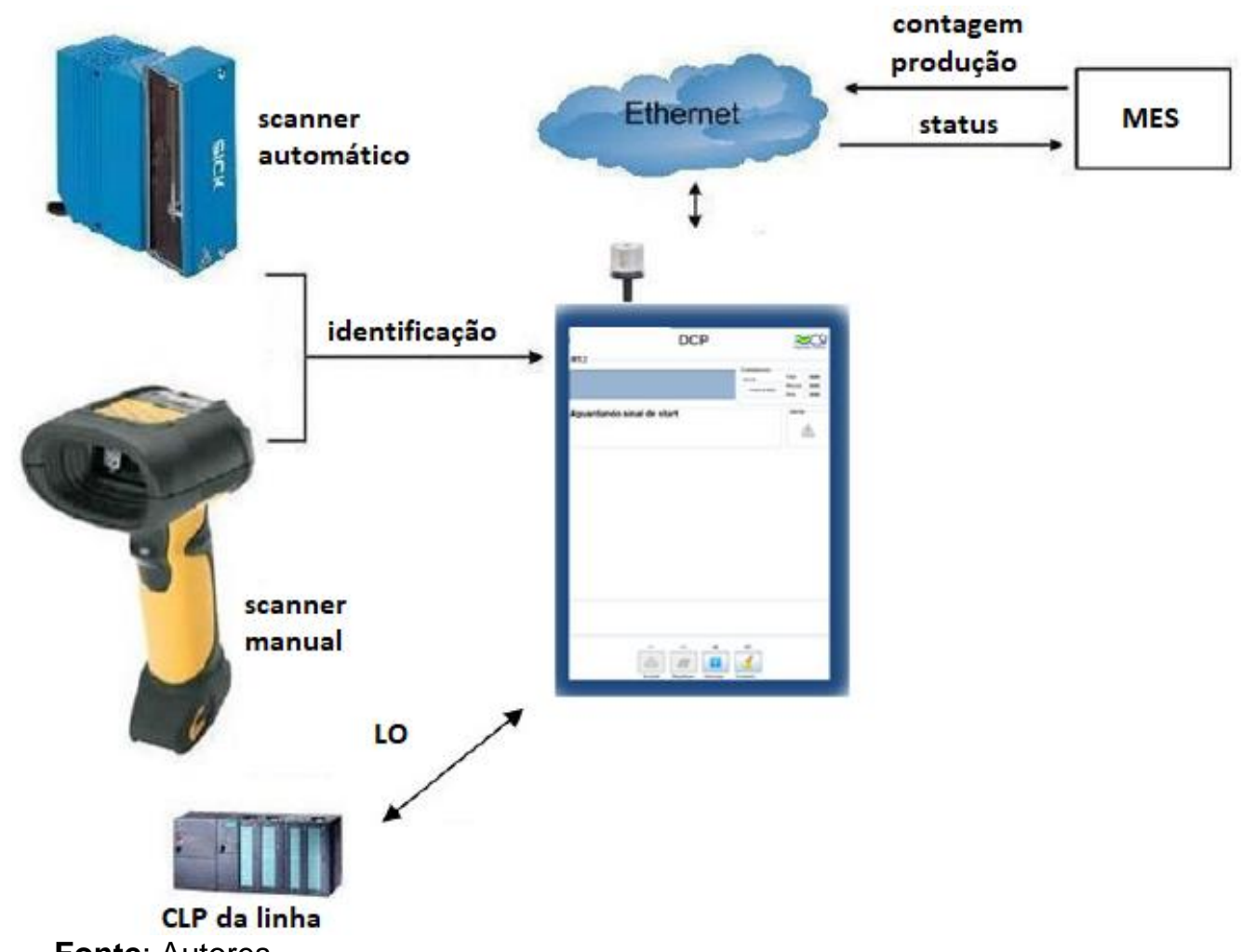

Fonte: Autores

O valor porcentual circulante para uma dada linha é calculado de acordo com a expressão:

$$
\% \text { circulante }=\frac{\text { circulante do produto }}{\text { programa de produção do produto }}
$$

Essa margem busca reduzir a recirculação desnecessária de produtos entre as duas linhas quando a diferença entre os percentuais de circulantes for menor ou igual à margem de cada linha. A estratégia de utilização da margem de $5 \%$ é aplicada baseando-se na distância de recirculação da linha.

$\mathrm{Na}$ situação em que ocorra um defeito no elevador de subida da linha B, o PCP poderá "zerar" a meta de produção dessa linha (levando a porcentagem do circulante da linha B para zero), implicando que todas as carrocerias Gol G6 sejam 100\% redirecionadas para a linha $A$.

Devido às restrições técnicas, torna-se impossível o redirecionamento das demais carrocerias para a linha B. Nesse caso, haverá parada de produção até que a manutenção solucione o problema. O Quadro 1 ilustra a exemplificação do processo. 
O modo de aplicação das interfaces inteligentes tem como meta identificar a carroceria e direcioná-la de acordo com algumas regras pré-definidas. O ciclo tem início quando o CLP envia um sinal de presença, indicando que há uma nova carroceria no posto de trabalho. Através de um leitor de código de barras, a DCP realiza a identificação da carroceria, através da leitura do código de barras, e inicia o processo de tomada de decisão de destino, ou seja, uma das linhas: A ou B. Caso não seja possível identificá-lo, o sistema de identificação remota por câmera deve ser acionado como contingência para identificação.

Quadro 1 - Exemplificação do processo

\begin{tabular}{ccccccc}
\hline Exemplo & $\begin{array}{c}\text { Linha e resultado } \\
\text { identificação do } \\
\text { produto }\end{array}$ & $\begin{array}{c}\text { Circulante (\%) } \\
\text { Linha A }\end{array}$ & $\begin{array}{c}\text { Linha B } \\
\text { (\%) }\end{array}$ & $\begin{array}{c}\text { Diferença } \\
\text { A e B (\%) }\end{array}$ & Decisão \\
\hline 1 & A sem restrição & 45 & 37 & 5 & 8 & enviado para linha B \\
2 & A sem restrição & 45 & 40 & 5 & 5 & permanece na linha A \\
3 & A sem restrição & 46 & 43 & 5 & 3 & permanece na linha A \\
4 & A com restrição & 45 & 37 & 5 & 8 & permanece na linha A \\
5 & B sem restrição & 37 & 45 & 5 & 8 & enviado para linha A \\
6 & B sem restrição & 40 & 45 & 5 & 5 & permanece na linha B \\
7 & B sem restrição & 43 & 47 & 5 & 4 & permanece na linha B \\
8 & B com restrição & 44 & 47 & 5 & 3 & enviado para linha A \\
Obs. & Linha A: produz todos os acabamentos dos produtos & & \\
\hline
\end{tabular}

Fonte: Autores

As regras do circulante direcionam as carrocerias para a linha $A$ ou linha $B$ interagindo com o volume de produção por turno. No fim do processamento, um sinal é enviado ao CLP para informar o resultado da operação.

A retirada do sinal de presença do produto por meio de sensores implica na interrupção imediata do processamento da DCP, independentemente do que esteja fazendo. Nessa condição, a DCP não irá gerar nenhuma sinalização ao CLP e retornará ao estado inicial, em que aguardará pela chegada da próxima carroceria.

Como contingência é utilizada uma ferramenta de passagem secundária, que serve para garantir a segurança do processo em vários casos como a queda da rede da fábrica, a falha no equipamento, a falha no sistema MES e outras. Na situação em que essa ferramenta é acionada, o CLP recebe um sinal informando a falha e aguarda uma decisão do operador.

Revista Produção Online. Florianópolis, SC, v. 20, n. 3, p. 749-771, 2020. 
Outra alternativa para remediar uma possível falha é colocar a DCP em modo by-pass. Nessa situação o CLP entende que a carroceria deverá seguir normalmente na linha atual. Esse recurso só poderá ser acionado com autorização da área de PCP.

$O$ aplicativo das interfaces inteligentes permite que a qualquer momento um operador entre com novos valores para o programa de produção em cada uma das linhas de produção A e B através de um microcomputador. Essa aplicação possibilita visualizar os valores correntes dos circulantes dos produtos comuns as duas linhas, e dos seus respectivos valores do percentual de circulante. $O$ aplicativo é utilizado exclusivamente pelo PCP que através dele realiza a atualização dos valores nas DCPs. A Figura 5 apresenta o comportamento da DCP durante o ciclo de operação desde $o$ instante da presença do produto até a sua liberação.

Figura 5 - Comportamento da DCP durante o ciclo de operação

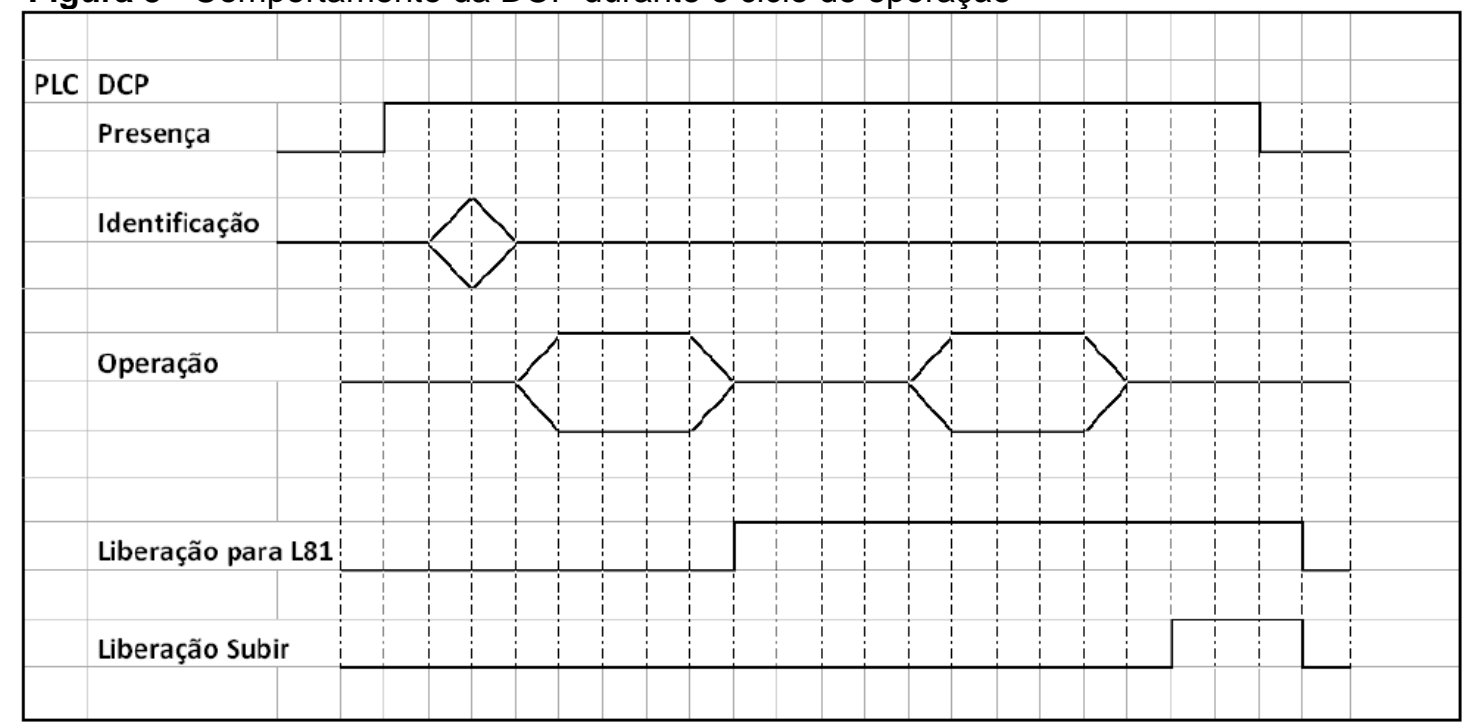

Fonte: Autores

\section{RESULTADOS E DISCUSSÃO}

O fluxo representado na Figura 6 ilustra a regra de circulante aplicada ao processo na época de desaceleração da produção do Gol G4 e a introdução do Gol G6 básico, ambos na linha B. Onde se lê porcentagem de circulante G4 é uma nomenclatura para indicar a linha B e porcentagem de circulante G6 é linha A. 
Para as DCP L760 e L765, o sistema permite a alteração do volume de produção e valor do circulante para as linhas A e B. Para este último ponto, só a área de suporte poderá alterar, o PCP só tem autonomia para alterar volume de produção.

Figura 6 - Fluxo da regra de circulante com mais um modelo na linha B

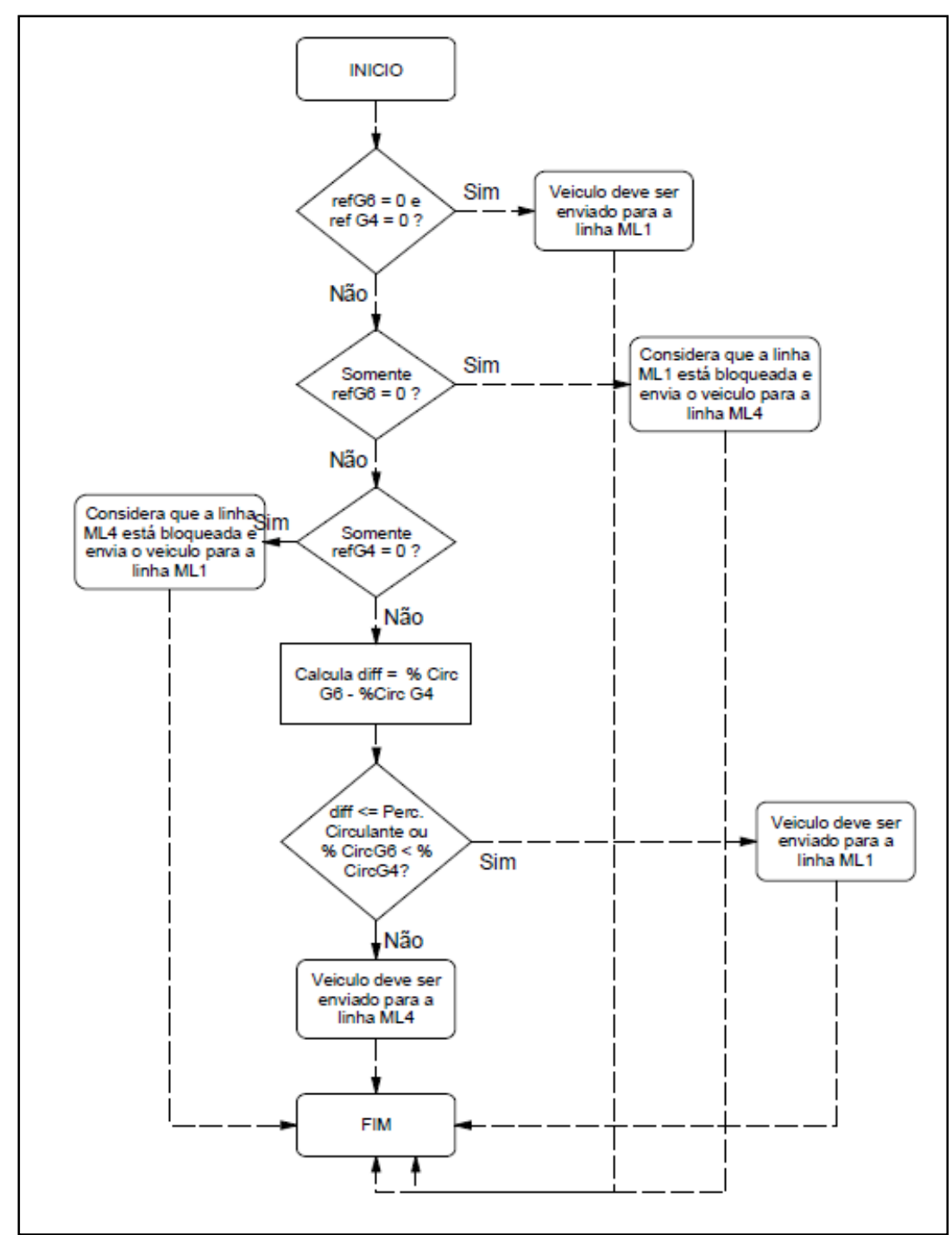

Fonte: Autores

Com esta implantação, obteve-se um resultado muito positivo, pois foi possível alcançar o volume previsto do Gol G6 em ambas as linhas. Como exemplo, a Figura 7 apresenta o relatório do FIS de 13 turnos, onde a média de redirecionamento foi de 10,85\% neste período. A sigla TNA 5 U3 com 0A1 significa Gol G6 básico que foi redirecionado para a linha $B$.

Revista Produção Online. Florianópolis, SC, v. 20, n. 3, p. 749-771, 2020. 
Além disso, houve redução das perdas, pois antes da implantação do sistema de flexibilização, a média de subida errônea era de 90 carrocerias / dia Gol G6 básicas restritas somente para a linha $\mathrm{B}$. Isto era devido à dificuldade do operador de identificar visualmente qual eram as carrocerias Gol G6 que podiam ir para a linha B e quais eram as que só podiam ir para a linha $A$. Este número refletia uma média de $15 \%$ da produção da linha B.

Figura 7 - Exemplo de relatório do FIS

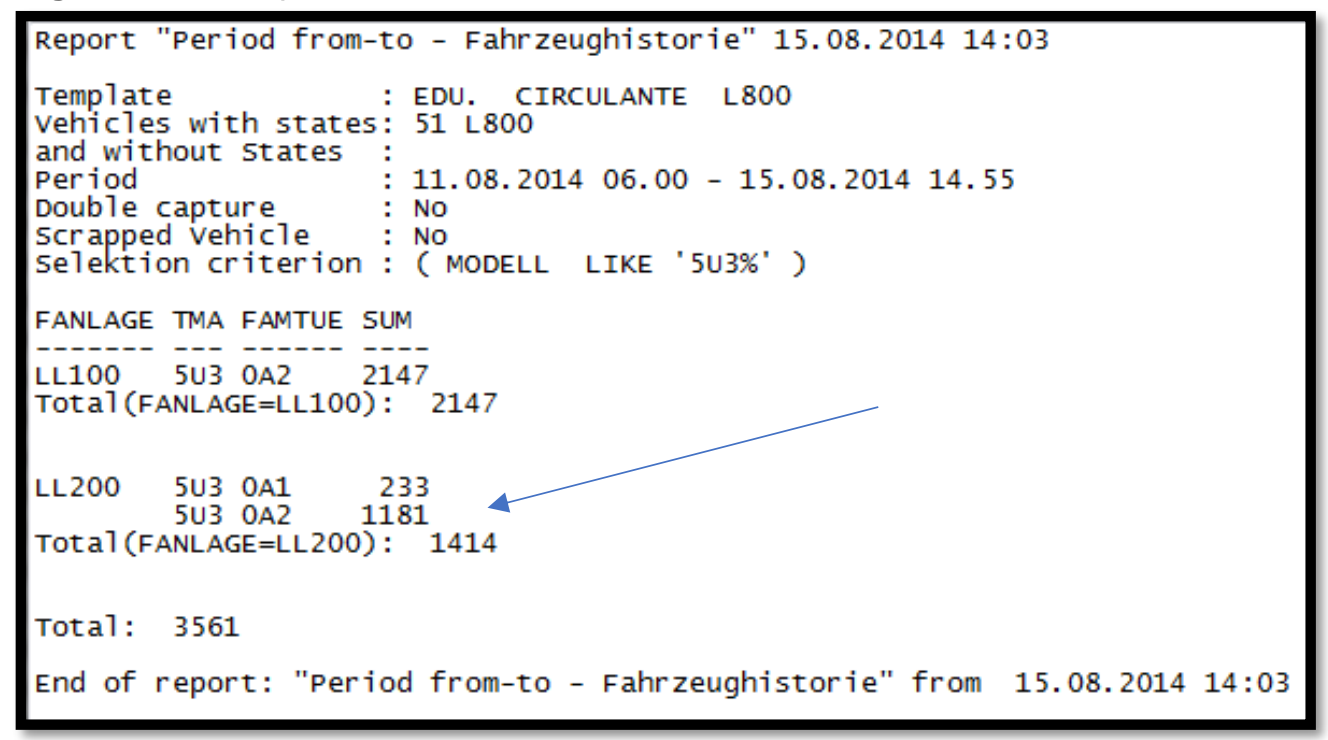

Fonte: Autores

Para ilustrar a melhoria, a Tabela 1 compara a quantidade de erros antes e depois da implantação do novo sistema, sendo analisado um horizonte de tempo nos 15 primeiros dias. Os números apresentados na Tabela 1 não são devidos a erros sistêmicos, mas sim carrocerias forçadas a subirem erroneamente pela produção. Estes casos são identificados através de arquivos gerados pelo sistema operacional, informando sobre algo que tenha ocorrido dentro do sistema.

Outro grande problema que acontecia, era a entrada de carrocerias "forçadas" no elevador da linha $A$, onde a leitura não era feita, e muitas vezes passavam carrocerias que já haviam informações de L8 no sistema, ou até carrocerias com status M1 - ponto que gera número de sequência definitiva de processo, o que geravam KNRs duplicados.

Tabela 1 - Comparação da quantidade de erros antes e depois da aplicação do novo sistema 


\begin{tabular}{ccc}
\hline dia & antes & depois \\
\hline 1 & 87 & 0 \\
2 & 88 & 0 \\
3 & 90 & 0 \\
4 & 91 & 1 \\
5 & 95 & 1 \\
6 & 82 & 2 \\
7 & 94 & 1 \\
8 & 88 & 0 \\
9 & 89 & 0 \\
10 & 91 & 0 \\
11 & 92 & 0 \\
12 & 93 & 1 \\
13 & 89 & 0 \\
14 & 92 & 0 \\
15 & 89 & 0 \\
\hline
\end{tabular}

Fonte: Autores

Quando detectados esses problemas, na maioria das vezes no próprio ponto M1, gerava a perda de uma carroceria, o que prejudicava o processo, pois os fornecedores JIT já haviam sido acionados e estas carrocerias precisavam ser retiradas imediatamente da linha.

A distância para extração dessas carrocerias é muito grande e não é simples, pois todos os fornecedores JIT precisam ser acionados e retidos. A sequência gerada a partir deste ponto precisa ser apagada e retirada do processo, assim como todas as impressões de sequenciamento de peças da linha. Além disso, o local de retirada é de difícil acesso, podendo a carroceria ser danificada, o que gera em muitas vezes retrabalho.

Com a implantação da flexibilidade na linha de processo com interfaces inteligentes controlando as restrições de forma automática, foi possível eliminar o problema do processo produtivo garantindo o volume de produção. Os erros que por ventura venham aparecer, são devidos a introdução manual das carrocerias na linha de produção.

Para constatar esses defeitos, foi implantado um programa de computador que é gerado pelo sistema operacional informando sobre algo que tenha ocorrido dentro Revista Produção Online. Florianópolis, SC, v. 20, n. 3, p. 749-771, 2020. 
da automação para visualização de qualquer tentativa "forçada" da produção em colocar manualmente a carroceria na linha errada. Isso pode ocorrer colocando o ponto de captura de dados no modo de passagem livre sem permissão.

A seguir são apresentadas a aplicação da teoria das restrições no sistema de interfaces inteligentes das linhas de montagem deste trabalho:

a) Identificar a restrição do sistema: As restrições de acabamento são facilmente identificadas, pois elas determinam o fluxo do sistema. Uma das linhas permite a passagem de todos os acabamentos e a outra, devido às restrições de montagem, só permitindo a produção de carrocerias Gol G6 básicos. Na linha A passam outros produtos exclusivos que dividem espaço com estes produtos comuns. No ponto de decisão da linha, o operador que fazia esse processo manualmente, sem a visão da quantidade destes produtos intercambiáveis que já estavam no circulante;

b) Explorar as restrições do sistema: Com as restrições identificadas, tanto de produto como de processo, foram instaladas as interfaces inteligentes para automação da gestão das linhas de processo para tornar o sistema mais eficiente e aumentar a taxa da capacidade do recurso. A empresa constatou que possuía uma corrente em que o recurso gargalo se encontrava no elo mais fraco e, para o fortalecimento desse, foi feito um trabalho de resistência através das interfaces inteligentes;

c) Subordinar todos os demais recursos à restrição: A interface inteligente faz a identificação do produto, consulta seus acabamentos no sistema FIS, verifica se há restrição, analisa o circulante deste produto e direciona-o para a linha correta e balanceada conforme a meta de produção. Esse passo consiste em subordinar todas as outras atividades à restrição. É o passo mais difícil porque questiona todas as práticas e procedimentos gerenciais tradicionais;

d) Elevar as restrições: Com esta aplicação, houve aumento de capacidade de fluxo na organização, pois foi evitado o direcionamento de produtos não compatíveis com a linha, recirculação destes no processo e a retirada forçada no início da linha de montagem após a chamada JIT. O 
gerenciamento de restrições não é uma simples receita, consiste na utilização do gerenciamento das restrições como um processo de melhoria contínua no processo produtivo.

A elevação das restrições é a pratica de ações de curto prazo, que adicionam capacidade ao recurso existente. Elevar a restrição significa trazer capacidade ao recurso há um nível mais alto, normalmente através de investimentos em equipamentos, mão de obra, etc.

e) Retornar ao passo inicial: Quando uma restrição for elevada, deve-se voltar ao passo inicial para identificar a próxima restrição do sistema. Neste estudo as restrições não se apresentaram de forma elevada, o que permitiu atingir os objetivos do trabalho.

\section{CONSIDERAÇÕES FINAIS}

A linha produtiva operava com o discernimento humano no direcionamento do produto, em que o mesmo tinha como processo decisório identificá-lo visualmente e, a partir do reconhecimento da tipicidade do produto, direcioná-lo às linhas produtivas "A" ou "B".

Com a instalação das interfaces inteligentes, foi possível que um mesmo modelo de automóvel pudesse ser fabricado em duas linhas de montagem, obedecendo as restrições do processo e a execução da identificação do veículo, realizada através de leitores de código de barras.

Com esta operação, foi possível garantir um processo automático com o direcionamento executado em 20 segundos, livre de erros quanto à fadiga humana em uma atividade repetitiva.

Outro ponto significativo foi que o PCP passou a controlar remotamente o volume de produção, obtendo online os dados e resultados do processo confiáveis, devido ao plano de contingência que atua de maneira automática e segura em caso de falhas.

É importante ressaltar que além do ganho de tempo e eliminação dos erros, conseguiu-se flexibilizar as duas linhas de produção, possibilitando a circulação de um produto com diferentes acabamentos em linhas restritas, não deixando de cumprir 
a meta de volume proposto, evitando recirculação e retirada forçada da carroceria após chamada JIT. Também permitiu que os demais modelos pudessem atingir suas respectivas metas de volumes.

Os resultados obtidos alcançaram as expectativas eliminando os retrabalhos, evitando as perdas de volume e criou-se uma situação favorável ao processo produtivo, pois as linhas tornaram-se flexíveis, podendo ser adaptadas para novas regras ou novos produtos.

O presente estudo comprovou a melhoria no processo a partir da implantação do sistema inteligente, em que foi possível verificar:

- Flexibilização na fabricação de um mesmo modelo de veículo em duas linhas de montagem;

- Eliminação da falha humana ocasionada por processo operacional repetitivo e cansativo;

- Otimização do tempo de processo;

- Obtenção de contingência para garantir a confiabilidade das informações e evitar paradas na linha de montagem;

- O PCP passou a controlar remotamente e online os dados do processo produtivo para garantir as metas de volume;

- A empresa tornou-se mais ágil para absorver os novos modelos de veículos e/ou novas estratégias de fabricação.

Outro ponto importante foram a transformação dos dados coletados em informações úteis ao processo como a identificação das restrições e as limitações técnicas de cada linha (tipo de CLP's, tempo de produção, quantidade de turnos, funcionamento dos transportadores, entre outros), que permitiram definir relações entre estes pontos para criar informações pertinentes gerando o conhecimento, que podem ser replicadas em outras operações semelhantes.

\section{REFERÊNCIAS}

ARAÚJO, F. J. Aplicação da TOC em uma estrutura hospitalar de grande porte: o uso da metodologia em um processo sistêmico nos serviços de internação. Revista de Gestão em Sistemas de Saúde, v. 2, n. 1, p. 161-180, 2013. https://doi.org/10.5585/rgss.v2i1.31

BABU, T. R.; RAO, K. S. P.; MAHESHWARAN, C. Application of TOC embedded ILP for increasing throughput of production lines. The International Journal of Advanced

Revista Produção Online. Florianópolis, SC, v. 20, n. 3, p. 749-771, 2020. 
Manufacturing Technology, v. 33, n. 7-8, p. 812-818, 2007. https://doi.org/10.1007/s00170$\underline{006-0508-4}$

CHOU, Y. C.; LU, C. H.; TANG, Y. Y. Identifying inventory problems in the aerospace industry using the theory of constraints. International Journal of Production Research, v. 50, n. 16, p. 4686-4698, 2012. https://doi.org/10.1080/00207543.2011.631598

COMAN, A.; RONEN, B. Managing strategic and tactical constraints in the hi-tech industry. International Journal of Production Research, v. 45, n. 4, p. 779-788, 2007. ttps://doi.org/10.1080/00207540600597237

CORBETT, T. Bússola financeira: o processo decisório da teoria das restrições. São Paulo: Nobel, 2005.

COX, J. F.; SPENCER, M. S. Manual da teoria das restrições. Porto Alegre: Bookman, 2002.

DALCI, I.; KOSAN, L. Theory of constraints thinking-process tools facilitate goal achievement for hotel management: A case study of improving customer satisfaction. Journal of Hospitality Marketing \& Management, v. 21, n. 5, p. 541-568, 2012. https://doi.org/10.1080/19368623.2012.626751

GIACON, E.; MESQUITA, M. A. D. Levantamento das práticas de programação detalhada da produção: um survey na indústria paulista. Gestão \& Produção, v. 18, n. 3, p. 487-498, 2011. https://doi.org/10.1590/S0104-530X2011000300004

GOLDRATT, E. M.; COX, J. A meta: um processo aprimorado contínuo. São Paulo: Nobel. 2002.

GUPTA, M.; SNYDER, D. Comparing TOC with MRP and JIT: a literature review. International Journal of Production Research, v. 47, n. 13, p. 3705-3739, 2009. https://doi.org/10.1080/00207540701636322

LAMBRECHT, M.; SEGAERT, A. Buffer stock allocation in serial and assembly type of production lines. International Journal of Operations \& Production Management, v. 10, n. 2, p.47-61, 1990. https://doi.org/10.1108/01443579010000736

MABIN, V. J.; BALDERSTONE, S. J. The performance of the theory of constraints methodology: analysis and discussion of successful TOC applications. International Journal of Operations \& Production Management, v. 23, n. 6, p. 568-595, 2003. https://doi.org/10.1108/01443570310476636

NEVES, I. C. B.; BARBOSA, I. C.; DE ARAÚJO, M. P.; DE AZEVEDO, A. A. Aplicação da teoria das restrições em uma indústria de laticínios: um estudo de caso. Revista Produção Online, v. 20, n. 2, 2020. https://doi.org/10.14488/1676-1901.v20i2.3664

PACHECO, D. A.; ANTUNES JÚNIOR, J. A. V.; LACERDA, D. P.; GOLDMEYER, D. B.; VON GILSA, C. Modelo de gerenciamento da capacidade produtiva: integrando teoria das restrições e o índice de rendimento operacional global (IROG). Revista Produção Online, v. 12, n. 3, p. 806-826, 2012. https://doi.org/10.14488/1676-1901.v12i3.981

PERGHER, I.; RODRIGUES, L. H.; LACERDA, D. P. Discussão teórica sobre o conceito de perdas do Sistema Toyota de Produção: inserindo a lógica do ganho da teoria das 
restrições. Gestão \& Produção, v. 18, n. 4, p. 673-686, 2011. https://doi.org/10.1590/S0104530X2011000400001

SABBADINI, F. S.; GONÇALVES, A. A.; DE OLIVEIRA, M. J. F. A aplicação da teoria das restrições (TOC) e da simulação na gestão da capacidade de atendimento em hospital de emergência. Revista Produção Online, v. 6, n. 3, 2006. https://doi.org/10.14488/16761901.v6i3.636

SCHOLZ, L. F. B.; GONÇALVES, A. A., DOS SANTOS, R. F.; SANTOS, N. M. B. F. Custos e rentabilidade em uma indústria de blindagens de veículos: um estudo de caso aplicandose conceitos da teoria das restrições. In: CONGRESSO BRASILEIRO DE CUSTOS, 19., 2012. [Anais...]. Bento Gonçalves, p. 1-14, 2012. Disponível em: https://anaiscbc.emnuvens.com.br/anais/article/viewFile/231/231, Acesso em: 15 set. 2020.

SILVA, A. L. E.; DA SILVA, V. C.; KIPPER, L. M.; DE CARVALHO, F. S.; MORAES, J. A. R. Aumento do desempenho fabril sob a luz da teoria das restrições: o caso de uma fábrica de colchões. Revista Produção Online, v. 17, n. 1, 2017. https://doi.org/10.14488/1676$\underline{1901 . v 17 i 1.2321}$

SOBREIRO, V. A.; NAGANO, M. S. A review and evaluation on constructive heuristics to optimise product mix based on the theory of constraints. International Journal of Production Research, v. 50, n. 20, p. 5936-5948, 2012. https://doi.org/10.1080/00207543.2011.638940

SOUZA, F. B. Do OPT à Teoria das restrições: avanços e mitos. Production, v. 15, n. 2, p. 184-197, 2005. https://doi.org/10.1590/S0103-65132005000200005

SPECTOR, Y. Theory of constraint methodology where the constraint is the business model. International Journal of Production Research, v. 49, n. 11, p. 3387-3394, 2011. https://doi.org/10.1080/00207541003801283

SPENCER, M. S.; COX, J. F. Optimum production technology (OPT) and the theory of constraints (TOC): analysis and genealogy. The International Journal of Production Research, v. 33, n. 6, p. 1495-1504, 1995. https://doi.org/10.1080/00207549508930224

TORRES, F. G.; COSTA, H. G. Teoria Das Restrições (TOC): caso de aplicação em uma empresa de confecção. Revista Gestão Industrial, v. 9, n. 2, 2013.

https://doi.org/10.3895/S1808-04482013000200008

TRIANA, V. K. O.; ROLÓN, Á. J. C. Programación óptima de la producción en una pequeña empresa de calzado en Colombia. Ingeniería Industrial, v. 35, n. 2, p. 114-130, 2014. Disponível em: http://scielo.sld.cu/scielo.php?script=sci abstract\&pid=S181559362014000200002 Acesso em 15/09/2020

VOTTO, R. G.; FERNANDES, F. C. F. Produção enxuta e teoria das restrições: proposta de um método para implantação conjunta na Indústria de Bens de Capital sob

Encomenda. Gestão \& Produção, v. 21, n. 1, p. 45-63, 2014. https://doi.org/10.1590/S0104$\underline{530 \times 2013005000009}$

WATSON, K. J.; PATTI, A. A comparison of JIT and TOC buffering philosophies on system performance with unplanned machine downtime. International Journal of Production Research, v. 46, n. 7, p. 1869-1885, 2008. https://doi.org/10.1080/00207540600972943 


\section{(c) 8}

Artigo recebido em: 07/09/2018e aceito para publicação em: 14/09/2020.

DOI: $\underline{10.14488 / 1676-1901 . v 20 i 3.3368}$

Revista Produção Online. Florianópolis, SC, v. 20, n. 3, p. 749-771, 2020. 